\title{
EL CUERPO DE LA VEJEZ DESDE UNA PERSPECTIVA DE GÉNERO. APROXIMACIONES DESDE $L A$ VEJEZ DE SIMONE DE BEAUVOIR
}

Dulce Suaya *

La vejez es un destino. Beauvoir, 1970, p. 39.

RESUMEN: El artículo sitúa la vejez en la sociedad contemporánea, etapa de la vida traspasada por múltiples significados asignados por el biocapitalismo (2014), que la estigmatizó con denominaciones despectivas. Entre las dominantes encontramos aquellas que representan al "viejo/a" como un "problema" "una carga insoportable" para las familias que, cada vez con mayor frecuencia, delegan su cuidado a instituciones especializadas, encontrándose muchas veces el anciano/a en un estado de abandono y desamparo. Desde esta perspectiva afirmamos que de todas las franjas etarias es sin duda la más desfavorecida, situación que se agrava al considerarse la perspectiva de género. La sociedad actual valoriza la juventud y la fuerza de trabajo socialmente productiva y a pesar de los avances insoslayables en este terreno, todavía sigue organizándose bajo una perspectiva patriarcal. Cabe preguntarnos ¿Qué pasa con las mujeres ancianas? ¿Son acaso doblemente desfavorecidas? ¿Pueden ser identificarse como doblemente dominadas? ¿Cuáles son las consecuencias subjetivas de su posición social? ¿Cómo esto se expresa en su corporeidad? El presente trabajo pretende tratar estas cuestiones y proponer el dispositivo Historia Vital

\footnotetext{
* Universidad de Buenos Aires, Buenos Aires, Argentina. E-mail de contato: dulcesuaya@gmail.com
} 
del Trabajo (HVT) como una herramienta terapéutica que busca contribuir con la elaboración de un proyecto de vida en el que se recupere, en la subjetividad y en el cuerpo de la mujer anciana, una capacidad de trabajo creativo susceptible de ser valorizado socialmente. A tal efecto se reflexionará sobre la obra "la vejez" de Beauvoir (1970) en tanto se considera que la autora aborda la problemática con valor no solo teórico sino también testimonial.

Palabras clave: Historia Vital del Trabajo (HVT). Género. Proyecto de vida.

\section{The aged body through a gender perspective. Approaches from The Old Body of Simone de Beauvoir}

ABSTRACT: The essay situates aging in contemporary society, a stage in life imbued by multiple meanings granted by bicapitalism (NEGRI, 2014) which stigmatizes it by using pejorative designations. Among the most commonly used designations we may find the ones that present the elderly as a "problem", or a "burden impossible to be carried" by the families that, increasingly and more frequently, delegate their care to specialized institutions, where the elderly are many times found in a state of complete abandonment and neglect. From this perspective we may state that among all age groups this is, without a doubt, the most underprivileged one. A situation that worsens when considered from a gender perspective. Present society values youth and the socially productive workforce and, despite the unquestionable improvement on this field, it still follows a patriarchal perspective. Therefore, we must ask ourselves: What is to happen to old women? Are they doubly underprivileged? Can they recognize themselves as doubly dominated? What are the subjective consequences of their social position? How is this expressed in their corporeity? The present paper intends to address these questions and propose the Vital History of Work mechanism (VHW) as a therapeutics tool that aims to contribute to the elaboration of a life project in which it retrieves, in the subjectivity of elderly women's body, an ability for creative labour susceptible to be socially valued. Over said effect we will reflect upon the work "The Coming of Age" by Beauvoir, in which the author approaches this problem, which not only has theoretical value but also testimonial value.

Keywords: Vital history of labour. Gender. Life project 


\section{INTRODUCCIÓN}

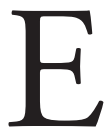

n cuanto se supone una exploración exhaustiva de la problemática, puede considerarse que para producir una reflexión sobre "la vejez" resulta imprescindible el trabajo que Simone de Beauvoir (1970) ha desarrollado sobre esta temática. Se encuentran en su texto múltiples niveles de abordaje: desde las circunstancias de la cotidianidad hasta experiencias de vida asociadas a personalidades que representan lo más alto de la cultura.

Simone de Beauvoir (1970) se propone quebrar el silencio sobre la vejez mediante un recorrido testimonial que busca recuperarla en términos vivenciales. Sin pretender hacer una historiografía, la autora repone la palabra del viejo. Es con el propio decir con lo que Beauvoir esboza un paisaje de historicidad. De este modo la vejez elude convertirse en objeto de la Historia.

La experiencia vivida recogida en la palabra tiene como su corolario una presencia insoslayable del cuerpo. Éste es el centro de toda apertura al mundo y a los otros, así como la razón de la existencia del tiempo. La vejez descubre un cuerpo que no es mero objeto, superficie donde acontece la decadencia biológica y cognitiva, sino un cuerpo vivido que, al transformarse en un cuerpo viejo, metamorfosea también el mundo que lo rodea y solicita. Así, por ejemplo, las actividades cotidianas como subir una escalera o levantar una valija dejan de ser acciones pueriles para convertirse en verdaderos obstáculos. De igual modo las relaciones con los otros se modifican. En primer lugar, en cuanto progresivamente el viejo/a deja de estar rodeado por sus pares. La pérdida de estos va seguida del establecimiento de nuevas relaciones sociales. Otras generaciones toman a su cargo las decisiones sobre su vida, su cuerpo y su futuro. Pero más centralmente en cuanto es la mirada del otro la que resulta fundamental en la constitución social y subjetiva del viejo/a. Beauvoir aclara "[...] la vejez se presenta con más claridad a los otros que al sujeto mismo [...]. El individuo que envejece no lo nota [...]". (BEAUVOIR, 1970, p. 340)

La cuestión de la vejez no se vive de modo análogo en hombres y mujeres. En Elsegundo sexo (2014) Beauvoir pone de manifiesto que las 
mujeres, en la sociedad contemporánea, aparecen como propiedad del hombre. Sus cuerpos operan como signos del estatus social masculino. Por consiguiente, un encabalgamiento de subordinaciones opera en el caso de las mujeres ancianas y pobres. En cuanto no sólo son desfavorecidas en términos materiales, sino que también se ven desprovistas de aquello que era su único bien: su cuerpo. En la sociedad burguesa contemporánea el cuerpo es un bien, pero no únicamente en tanto fuerza de trabajo. Un cuerpo bello, elegante es apreciado en la medida en que puede convertirse en signo. La mujer reducida a su aspecto corporal es signo del poderío masculino, de status social. Beauvoir ha señalado esta operación a propósito de la relación de dominación masculina;

En la sociedad burguesa uno de los papeles asignados a la mujer es el de representar: su belleza, su encanto, su inteligencia, su elegancia son los signos exteriores de la fortuna del marido con el mismo título que la carrocería de su automóvil. Rico, la cubre de pieles y alhajas. Más pobre, encomiará sus cualidades morales y su talento de ama de casa; el más desheredado, si ha conseguido una mujer que le sirva, cree poseer algo en la tierra. [...] pero la mujer no sólo alaga la vanidad social del hombre. Le permite también un orgullo más íntimo; le encanta el dominio que ejerce sobre ella. [...] todo hombre exhibe a su mujer porque cree mostrar así sus propios méritos. (BEAUVOIR, 2014, p. 179)

La mujer es confinada a ser un cuerpo objetivo, un cuerpo que se circunscribe a su propia representación y en el que los otros encuentran placer. No importa su experiencia de la corporalidad, ni tampoco es ella quien resulta sujeto de deseo. Son los otros y fundamentalmente los hombres quienes hacen del género femenino un objeto de contemplación y deleite, o llegado el caso, un signo de su posición social. Este fenómeno es harto evidente en la circulación de imágenes y discursos mediáticos contemporáneos, aunque ya tenía vigencia para la sociedad francesa de mediados de siglo XX. 


\section{HACERSE VIEJO O ESTAR EN BÚSQUEDA DE UN TIEMPO PERDIDO}

La vejez no es algo que acontezca de modo repentino. Y mucho menos lo es asumir subjetivamente esa posición. Son numerosas y de diversa índole las condiciones que se ven transformadas en este devenir. Tanto las biológicas como las sociales y económicas. En relación al cuerpo femenino la menopausia es una de las condiciones biológicas que afectan subjetivamente a las mujeres y las solicitan a reconocerse como viejas. $\mathrm{La}$ pérdida de su fertilidad aparece como un rito de pasaje que, en algunos casos, puede suscitar grandes montos de sufrimiento psíquico. Ante éste se observan fantasías sustitutivas que tienen por función mantenerse en una temporalidad desfasada: fijarse afectivamente en un tiempo que ya ha sido perdido.

Puede leerse a la luz de Beauvoir una suerte de tipología de los diferentes modos de metabolizar el advenimiento de una nueva etapa: las mujeres maternales, las infantiles y las sensuales.

La mujer maternal es aquella que, frente a la pérdida de fertilidad en el momento de la menopausia, asume como fantasía restitutiva el deseo de ser madre. Se ha dado el caso de mujeres que llegan a adoptar niños o incluso, cuando las condiciones biológicas lo permiten, tener los propios. La infantil es aquella que ante estas condiciones sufre una suerte de regresión. Se fija a un tiempo pasado asumiendo comportamientos infantiles. La sensual, es aquella que restituye su pérdida buscando mantenerse como objeto erótico y tiene amantes.

Estas fantasías manifiestan que el devenir viejo es un proceso complejo que, en la mayoría de las ocasiones, no acontece sin sufrimiento psíquico. Si bien, por lo general, este emerge como un denominador común en todos los momentos de transición, (del nińo al adolescente, del adolescente al adulto), en el pasaje a la vejez se incrementa, en cuanto es la experiencia subjetiva del carácter finito de la vida la que asume protagonismo.

La condición biológica y el enclaustramiento social progresivamente aíslan al viejo: de sus amigos, de sus hogares, de sus actividades laborales. Entre los recién llegados a la tercera edad es donde más se 
evidencia este malestar psíquico y físico. Nuevos procesos orgánicos acontecen, nuevas funciones sociales advienen y el pasado comienza progresivamente a ganar peso frente a un horizonte de futuro cada vez más limitado.

En ocasiones los mecanismos inconscientes que se ponen en juego consisten en mantener conductas anteriormente habituales sin reconocer las transformaciones objetivas del entorno al que estas se aplicaban. Así, por ejemplo, entre quienes recientemente han sido jubilados, se observan la mantención de hábitos asociados al trabajo: continúan levantándose en los horarios acostumbrados, sintiendo la exigencia de hacer actividades productivas y en los casos en la que sus profesiones lo habilitan, continúan ejerciéndolas, pese a que ya nadie los reconozca ni los retribuya por ello. El “joven” viejo, el recientemente jubilado, permanece adherido afectivamente a un pasado perdido, donde él se reconocía subjetivamente. Cuando esto sucede, se observan actitudes depresivas. El viejo no sabe qué hacer con su tiempo, sufre el tedio y el abandono y finalmente entra en un estado de desafección y desgano.

Son relativamente pocos los casos en los que la transición a la vejez es apertura para el desarrollo de un proyecto de vida nuevo. Desde el sentido común, el viejo no cambia, sus comportamientos resultan demasiado firmes y sedimentados como para permitir la emergencia de lo novedoso. Sin embargo, el viejo no tiene por qué considerar a esta etapa bajo la clave de la decadencia y la degradación. No es natural este modo de vivir y habitar la vejez. Numerosos estudios han puesto de manifiesto que su rol y su función social se construyeron y elaboraron históricamente. Simone de Beauvoir no ha desatendido al carácter histórico de la vejez. Por el contrario, dedicó buena parte de su ensayo a reconstruir el modo en que en diferentes momentos históricos (desde el s. XV hasta la sociedad francesa de mediados de siglo XX) y espacios geográficos (Grecia, Italia, Francia, Rusia), vivían y constituían esta etapa de la vida.

Sin embargo, han sido relativamente escasas las investigaciones que, en el ámbito de la psicología, han propuesto formas de atención específica a este problema. Se encuentra cierto vacío tanto desde el punto de vista teórico como en materia de atención clínica que se haya especializado en los procesos de transición a la vejez. Y en lo particular en lo relativo a una de los mayores cambios que acontecen durante este 
periodo: la jubilación. Cuando un proyecto de vida ha sido construido en relación al empleo, la finalización de esta etapa suele ir asociada con una pérdida del sentido de la vida. La lógica del mercado laboral contemporáneo desplaza al viejo como un sujeto socialmente improductivo, considerándolo como no apto para la realización adecuada de su actividad y desconociendo la maestría práctica que los empleados viejos tienen respecto de su trabajo. Por ejemplo, un estudio ha demostrado que los trabajadores más viejos del Servicio del Correo no necesitaban pesar las cartas porque al tocarlas conocían su peso de inmediato. Bajo este encuadre, el dispositivo de intervención psicosocial Historia Vital del Trabajo (HVT) encuentra su razón de ser. En cuanto propone un despliegue de estrategias que dan cuenta de la dinámica de un proceso de subjetivación que reubican al sujeto como portador de un saber socialmente productivo.

\section{HISTORIA VITAL DEL TRABAJO. EN BÚSQUEDA DE LA CREACIÓN DE UN FUTURO}

El HVT es un dispositivo teórico-práctico cuyo propósito consiste en contribuir a la recuperación de una relación con el trabajo. Esta propuesta se erige sobre una distinción capital entre "empleo" y "trabajo". Si el primero se lo define como la inscripción de la fuerza de trabajo en las relaciones de producción contemporáneas, el segundo refiere a una capacidad creadora y transformadora que el sujeto tiene, fruto de un saber aprehendido en su experiencia personal e histórica.

La aplicación del dispositivo a los trabajadores en situación de prejubilación apunta a remover la memoria histórica de los sujetos en su trayectoria laboral para recuperar a partir de allí, una relación nueva con sus potencialidades y capacidades. A través del relato de situaciones pasadas, en donde los sujetos llevaban a cabo sus tareas laborales, el HVT apunta a situar al sujeto en situaciones de satisfacción. "La intervención del HVT se orienta a la apropiación de las huellas que nombran al sujeto como sujeto trabajador, promoviendo la construcción del proyecto futuro y resignificando la relación del sujeto con su potencial creativo [...]". (SUAYA, 2010, p. 63) 
El HVT apunta a remover la memoria histórica del sujeto, en cuanto a su trayectoria laboral, para conducirlo a recordar una escena pasada de satisfacción durante el desarrollo de sus actividades. La evocación del recuerdo de un pasado investido afectivamente desplegado en la escena narrada orienta al sujeto a reconocerse como alguien capaz, portador de habilidades y saberes, y contribuye a la deconstrucción de las representaciones que limitan sus actividades actuales. A partir de allí un proyecto de vida nuevo puede ser desplegado, no como negación del pasado sino imbricado con él. La búsqueda de un tiempo perdido es la recuperación de un tiempo por venir, donde la subjetividad vuelve a reconocerse portadora de un saber hasta entonces supuestamente olvidado.

El relato remueve el espacio de memoria produciendo recuerdo. El Yo narra en tiempo presente una escena del pasado. La escena recordada es siempre una construcción encubridora. La reminiscencia otorga un cariz nostálgico a la escena evocada y la rememoración actualiza ese pasado presentificándolo, borrando la dualidad yoica y estableciendo una imbricación pasado-presente. (SUAYA, 2010, p. 63)

El dispositivo Historia Vital del Trabajo propone entonces hacer hablar al espacio de memoria. Se busca que el sujeto nombre su saber cómo sujeto trabajador a partir del encuentro con la marca mnémica que se edita en el presente.

\section{METODOLOGÍA DE APLICACIÓN DEL HVT}

En cuanto a su aplicación, el dispositivo HVT tiene una modalidad de implementación grupal. Se trata de una dinámica de trabajo semanal, aproximadamente de una totalidad de ocho encuentros de una hora y media de duración.

En el curso del desarrollo del dispositivo en primer lugar se avanza sobre el relato de las trayectorias laborales de los participantes al tiempo que en la actualización del perfil de sus intereses, habilidades y 
destrezas se aplican estrategias propias del proceso de orientación vocacional educativo ocupacional (OVEL).

Posteriormente, los integrantes del grupo elaboran un trabajo en conjunto de apreciación de sus pares. De tal modo se trata de que cada uno de los participantes tenga la oportunidad de contrastar su auto imagen con la imagen que genera en su par. A partir de este trabajo grupal de heteroevaluación se busca producir un reposicionamiento subjetivo: un reconocimiento y apropiación de la identidad como sujeto productivo.

Hacia los últimos encuentros los participantes producen una autoevaluación escrita y un proyecto de vida construido en tiempo futuro (habrá de ser). El HVT dispone así de dinámicas grupales de trabajo en las que se le sirve a los sujetos de las herramientas adecuadas para avanzar en la producción de un nuevo proyecto de vida, que no presupone la negación del pasado sino una imbricación creativa y productiva con él. El viejo, su vida, su cuerpo y su futuro encuentran en el HVT una herramienta idónea con la cual resignificar sus habilidades.

Es pertinente ilustrar tal afirmación con la aplicación del HVT que se ha realizado en los proyectos de investigación subsidiados por la Universidad de Buenos Aires desde la Secretaría de Ciencia y Técnica (UBACyT 1998-2000, 2001-2003). Incluimos en este texto uno de los resultados obtenidos que consideramos meritorio de destacar. Se trabajó con 101 maestras afiliadas al Sindicato Unión de Trabajadores de la Educación (UTE), las cuales debido a licencia psiquiátrica no podían realizar su trabajo en el aula. Frente a la necesidad de un cambio de actividad, se elaboró un proyecto que les permitía seguir trabajando. El 90\% eligió actividades vinculadas a la enseñanza fuera del contexto áulico (tutoría, orientadora de textos, entre otras). La aplicación del HVT conllevo a la construcción de un entramado discursivo producido en los ochos encuentros con el decir de las docentes; se elaboraron recursos de afrontamiento al asedio moral que sistematizamos y conceptualizamos como: Recursos protectores, Recursos Mitigadores, Recursos Espaciadores, Recursos Expresivos y lúdicos, Recursos Elaborativos, Sublimatorios y Creativos. Dejamos consignados en la bibliografía las referencias a las investigaciones. 


\section{CONSIDERACIONES FINALES}

En este texto, hacemos un llamado a los lectores a la reflexión sobre el lugar que ocupa en nuestros tiempos, los "hombres y mujeres de edad". El aumento de la expectativa de vida ha producido un cambio importante en la pirámide demográfica de la mayoría de los países del mundo. Queremos destacar en el texto, la asignación hecha por el capital de las personas de edad como una mercancía, así como las estrategias implementadas para este fin, transformando en enfermos, tanto física como psíquicamente, favoreciendo así un aumento de los lucros de los laboratorios y clínicas geriátricas. A nuestro entender, la visibilidad de este problema puede contribuir al aumento de la resistencia a este tipo de choque. Al mismo tiempo, se propone otro enfoque sobre el tema mediante la implementación del dispositivo Historia Vital del Trabajo (HVT) cuya metodología tiene como principios, el respeto, los derechos humanos, la dignidad de la persona anciana, reconociendo a través de la narración de su historia, sus habilidades y capacidades, y su potencial creativo. Otra mirada a nuestro viejo/as es posible.

Si Simone de Beauvoir nos recordaba que la vejez es un destino, no por ello debe entenderse una instancia abúlica y decadente de la existencia, sino una nueva etapa creativa y potenciadora de las habilidades sedimentadas en los cuerpos.

\section{REFERENCIAS}

BEAUVOIR, S. La vejez. Buenos Aires: Sudamericana, 1970. . El segundo sexo. Buenos Aires: Debolsillo, 2014.

NEGRI, A. Biocapitalismo y constitución política del presente. In: CERBINO, M.; GIUNTA, I. (Comp.). Biocapitalismo, procesos de gobierno y movimientos sociales. Quito: FLACSO, Sede Ecuador, 2013, p. 19-42.

PROGRAMACIÓN Cientifica UBACyT 1998-2000. Proyecto de Pesquisa Reorientación Profesional a Docentes en Licencia Psiquiatrica con Inclusión de la Historia Vital Laboral. Evaluación de su Impacto en la Reducción del Sufrimiento Psíquico. Buenos Aires: UAB/Facultad de Psicología. 
Disponible: <http://www.psi.uba.ar/investigaciones.php?var=investigaciones/ ubacyt/1998-2000/suaya.php>.

PROGRAMACIÓN Científica UBACyT 2001-2003. Proyecto de Pesquisa Prevención y Promoción de la Salud Mental Docente Mediante la Utilización del Instrumento HVT (Historia Vital del Trabajo). Buenos Aires: UAB/Facultad de Psicología. Disponible: <http://www.psi.uba.ar/investigaciones. php? var=investigaciones/ubacyt/2001-2003/resumenes.php\&id=187> .

SUAYA, D. Historia Vital del trabajo: herramienta de atención en salud colectiva. Buenos Aires: Cooperativa Chilavert Artes Gráficas, 2010.

Recebido em 01 de junho de 2015.

Aprovado em 15 de setembro de 2015.

DOI: http://dx.doi.org/10.1590/CC0101-32622015150382 